\title{
Influence of remetalizer "Rimet" on treatment of the bearing alloy
}

\author{
Georgi Komitov \\ Department of Agricultural Mechanization - Agricultural University - Plovdiv, Bulgaria
}

\begin{abstract}
At repair-restorely works exist technological influence on work surface of details, which sizable the intensive lower of running rubbing and wear out processes. Between rubbing surfaces begin forming of new layer with thickness in proportion of the wear out, in result of this the friction between the surfaces is decrease. This article present the influence of additive "Rimet" to variation of wear out, change of roughness and speed of wear out. The research are conducted on machine for rubbing and wear out "MRW-1", over rubbing couple in type "tempered steel - bearing alloy". At research are received datas for weight change on roll and bearing alloy AO-20 and BO-30. also the values of the change of the geometry of the rolls and the change of the rolls and bearing alloys roughness by several sections. The received results are giving possibility for rating of ongoing processes at using additive "Rimet" on tracking of treatment and wear out stability of rubbing couples from "shaft-bearing".
\end{abstract}

\section{Introduction}

The working surface of the parts of the transport technique during the application of various repair and restoration operations is an extremely important period of the work of the joints, which influences the durability of the exploitation process and the economic indexes performance of the machines $[1,2]$.

The bearings are mechanisms, most often machine elements that limit relative movement to certain directions and reduce friction between moving parts. Typical example are axial bearings that facilitate rotation about one axis, but limit the displacements in transverse direction [1-3].

The growing technical and production requirements to internal combustion engines and other industrial machinery placed them in the ordinary course of working regimes at high levels of mechanical, thermal and chemical loadings. The lubricating medium as an irrevocable part of the machine materially influences on the parameters of friction and wear $[1,4]$.

One of the factors influencing the treatment regime is the use of various additives to the oils [2].

The third - generation nanoremetalizer „Rimet“ (figure 1) contains three - component alloys from copper, lead, antimony (cu - sn - sb). When working the engine, the nanoparticles fill through the pressure and temperature even the smallest microwells that form on the contact surfaces. According to the distributor "Rimet" there is a complex of additie to reduce the friction, which in itself increases the dynamics and power of the engine [5].

The exploitation properties of the parts and their service life are largely determined by the quality of their working surface. The real working surface always has a certain roughness of different shape and height, which is formed during machining or rebuilding [6].
Under the treatment is meant the process of modification of the geometry of the surface of friction and physicomechanical properties of the surface layers of the material in the initial period of friction, to decrease the work of friction, temperature and intensity of wear [6].

The treatment is divided into three stages associated with the reduction of micro and macroinequality and achieving optimal roughness [6].

The first stage is characterized by a reduction of the micro-inequality, an increase of the contact area and a decrease of the contact voltages [6].

During the second stage there is a decrease in the magnitude of wear, of the mechanical losses, with partial straightening of the errors in the geometric form [6].

The third stage is characterized by wear stabilization [6].

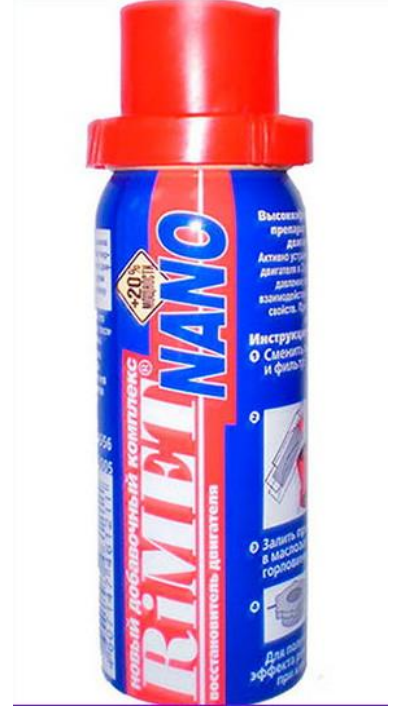

Fig. 1. View of tested addititve.

\footnotetext{
*Corresponding author: gkomitov@abv.bg
} 


\section{Method of examination}

The purpose of this study was to determine the influence of remetalizer "Rimet" on variation to the quality of the working surface of the details in the first stage of treatment, assessed with the variation weight of rolls, bearings and couples as well as with the change of their roughness.

Comparative study of the effect of the additive "Rimet" on variation of tribotechnical characteristics of the working surface in the process of treatment is carried out on the stand for friction and wear under the "MRW-1 " by the scheme "roll segment" in terms of liquid lubrication in the relative speed of drag and 2,35 m/s speed $900 \mathrm{~min}^{-1}[1,2,6]$.

Object of the study is etalon samples are made of steel 45, hardened with "high frequency current" to hardness 48$52 \mathrm{HRC}$, working in friction couple with bearing alloy on copper base BO-30 and on aluminum based AO-20 [1, 2, 6].

The force on the bearing is $100 \mathrm{daN}$, which provides a pressure of $5 \mathrm{MPa}$ and a tribotechnical characteristic in the admissible loads values of sliding bearings in the transport technique. The loading of the friction couple is made stepless at $1.0 \mathrm{MPa} / \min [1,2,6]$.

For the input parameters of the accepted model of study (figure 2) the quality of the oil $\mathrm{P}_{\mathrm{O}}$ and the type of the friction couple $\mathrm{T}_{\mathrm{C}}$ are accepted $[1,2]$.

The quality of the oil is determined by the type of oil and added remetalizing agent. In the specific case of comparability of the results with previous studies, the oil M10D has been selected.

Was mentioned that the friction couple is sliding and is by the scheme "roll-segment".

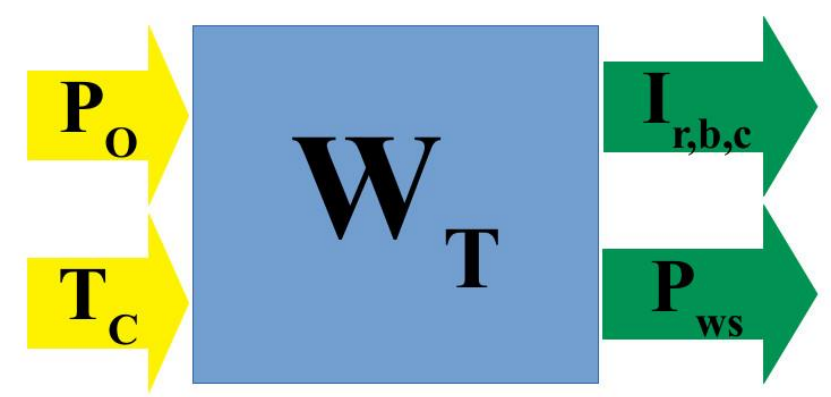

Fig. 2. Model of experiment:

$\mathrm{W}_{\mathrm{T}}$ - work of treatment; $\mathrm{P}_{\mathrm{O}}$ - property of oil; $\mathrm{T}_{\mathrm{C}}$ - type of treatment's couples; $I_{r, c o n, c}-$ wear out of roll, bearing and couple; $\mathrm{P}_{\mathrm{WS}}-$ property of work surfaces.

For output parameters of the selected model are accepted the wear of the roll, bearing and couple $I_{r, b, c}$ and the quality of working surface $\mathrm{P}_{\mathrm{ws}}[1,2]$.

Evaluation of wear is made by the weight method at change the weight of the roll and the bearing through electronic scale with an accuracy of $0,0001 \mathrm{~g}$ and by direct measurement of the linear dimensions of the rollers in four planes through $45^{\circ}$.

For credibility, experiments were performed with three times repeatability.

\section{Experimental results}

The results of the experiment after the corresponding statistical processing are shown in figure 3-8.
In figure 3 shows the variation in roll wear as assessed by weight change. It is noticeable that during the first $30 \mathrm{~min}$ the intensity of the roll weight variation is highest for both types of bearings $\mathrm{AO}-20$ and $\mathrm{BO}-30$, this variation being greater for the aluminum alloy. This change for rolls working with AO-20 antifriction alloy is $1,1 \mathrm{mg}$ for the entire tereatment period. For rolls working with antifriction alloy BOS-30 this change is $3,7 \mathrm{mg}$. This is because the babbitbased antifriction material is known to have weaker antifriction properties. Negative variation of weight rolls working with AO-20 is explained by the likelihood that part of antifriction material to a surface of the roll due to shearing a microrough of the surface layers of materials. After 45 minutes of treatment, stabilizationr of the weights of all rolls was noticed, and it can be said that the treatment process was completed.

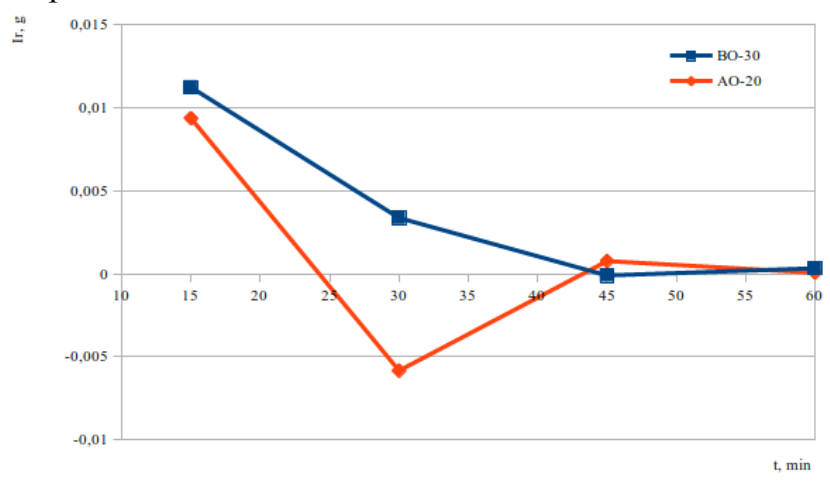

Fig. 3. Wearout variation of roll weight.

The position on the bearings is almost identical to that of the rolls (Figure 4). The difference is the magnitude of wear of antifriction materials. As a result of the treatment, the bearings from $\mathrm{AO}-20$ have lost $0,7 \mathrm{mg}$, whereas those from the BO-30 in result to their harder structure have lost 12,1 $\mathrm{mg}$. This great wear of antifriction material is probably explained by its very structure and inability in her go in nanostructure the remetalizer.

In general, the friction couples from roll and antifriction material AO-20 lost 1,7 mg (Figure 5) versus 15,8 mg for couples roll and antifriction material BO-30. The graph shows the better running of the processes in the pair with the anti-friction material AO-20.

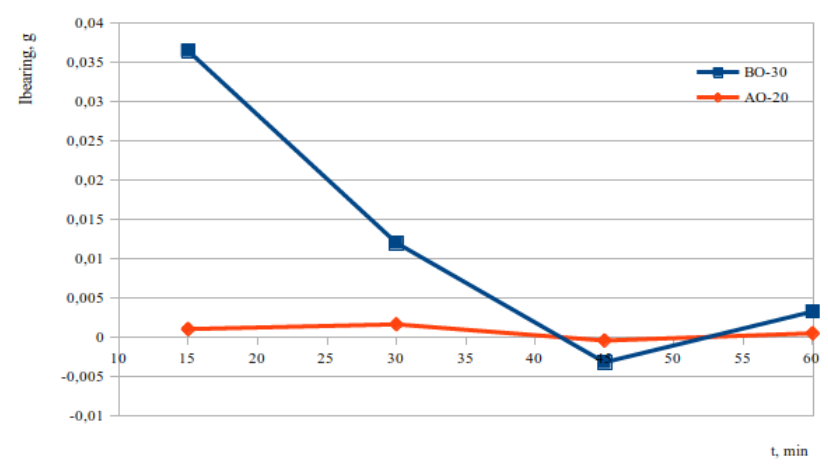

Fig. 4. Variation of bearing weight.

Analyzing the variation of rolls size variation (Figure 6), there is some reduction in roll size in section I-I on a roll working with antifriction material based AO-20. For the entire treatment period, the mean change in roll dimensions working with bearings on the base AO-20 is $16,5 \mu \mathrm{m}$, 
whereas those rolls working with an antifriction material BO-30 are of the order of $0,4 \mu \mathrm{m}$. This anomaly can be explained by the introduction of the "nanostructures" in the layer between roll and the bearing is made and in the result of the friction force is obtained an amendment to the size of the rolls under the action of hard nanostructures "Rimet", falled in oil wedge of the couple.

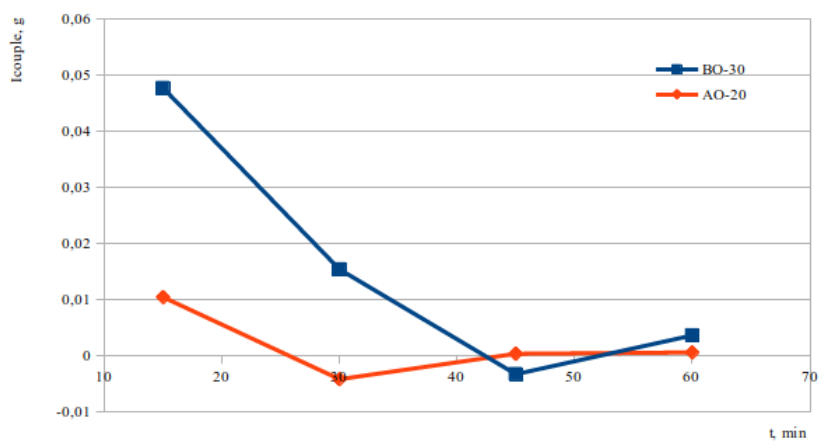

Fig. 5. Wearout variation of couple.

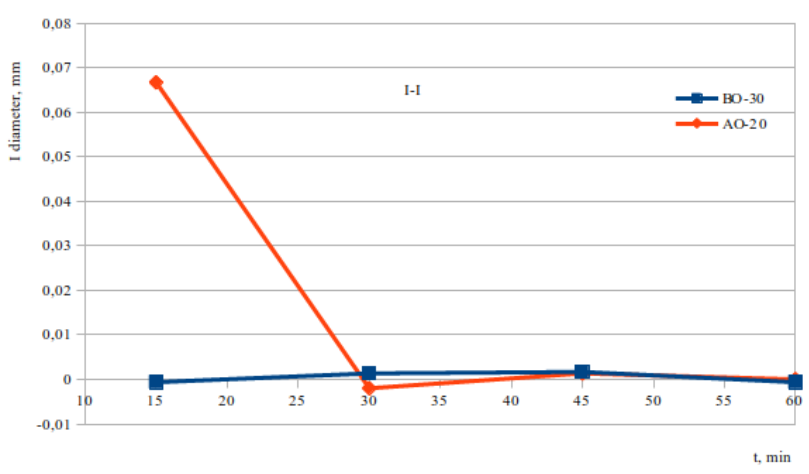

Fig. 6. Wearout variation of roll diameter.

In Figure 7 shows the variation in the roughness of the rolls working with the bearings on base AO-20 and BO-30. Here it is clearly stated the above-mentioned circumstance that the hard layer of BO-30 does not predispose the penetration of solid nanoparticles into the couple's oil wedge. In both cases of the bearings with AO-20 and BO-30, the roughness in the initial period to 30 minutes increases, and then stabilization of the roughness process is observed, and this process is clearly expressed in the graph. There is a certain change in the roughness of rolls working with an antifriction material BO-30 due to the solid structure of alloy.

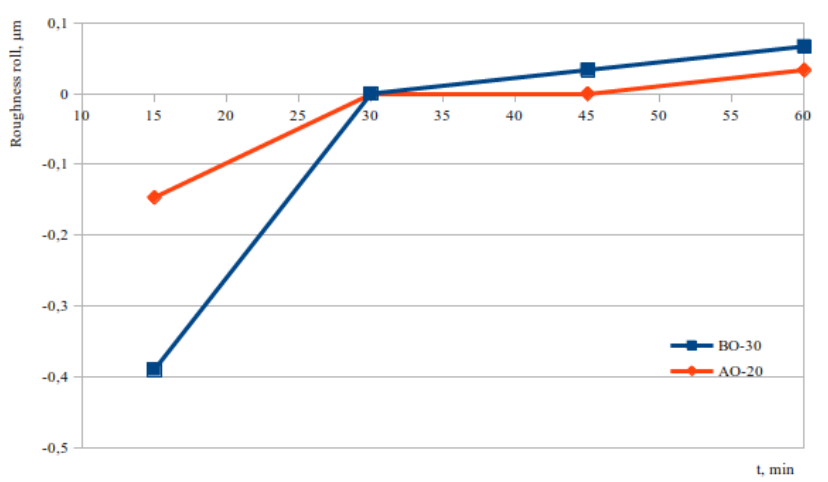

Fig. 7. Variation of roll roughness in section I-I.
This amendment for the whole period of the test in section I-I was within the $0,073 \mu \mathrm{m}$ for rolls working with antifriction alloys based on BO-30 and $0,028 \mu \mathrm{m}$ for rolls, working with antifriction alloys based on AO-20.

The change in roughness of the bearings in section I-I is shown in Figure 8. Here, as with rolls, the greater roughness is that of the bearings using an antifriction material based on BO-30. This variation is within $0,34 \mu \mathrm{m}$, compared with 0,8 $\mu \mathrm{m}$ at the alloy based of AO-20. As mentioned above such deviations can be explained by the penetration of the solid nanoparticles of the remelizer into the oil wedge of couple's. When the base is softer, as is the case with AO-20, it is possible that these nanoparticles under the action of friction forces and the oil tub are beat up in antifriction material and form a protective film that comes into contact with the oil film of the rolls. The friction is transferred from the contact surface to the nano lavel and it is carried out between the newly formed film.

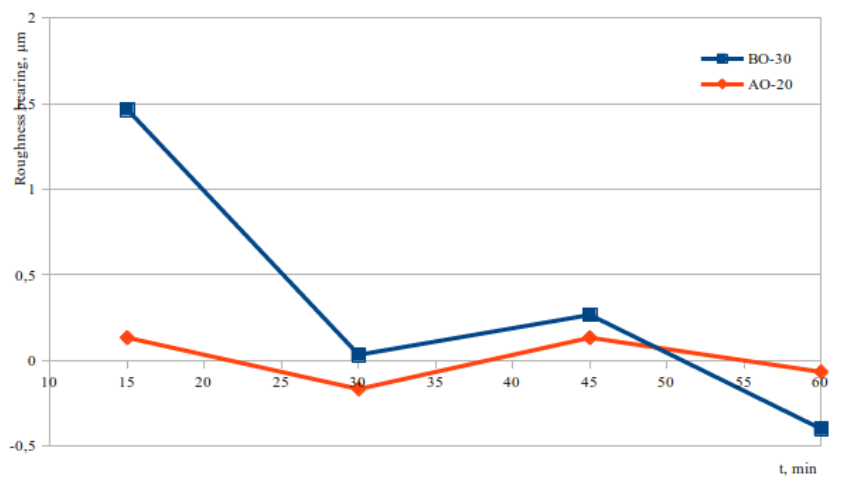

Fig. 8. Variation of bearing roughness in section I-I

On the other hand, if an antifriction alloy of the BO-30 type is present, nanoparticles are difficult to move into micro rough and begining the friction between the base material and the nanoparticles.

\section{Conclusions}

The application of remetalizer "Rimet" results in increased wear of the weights and dimensions of rolls and bearings, based on the antifriction material BO-30. For rolls and bearings at base $\mathrm{AO}-20$ this wear decreases.

The treatment process ends in fact 45 minutes from the start of the work.

The roughness of the rolls and bearings based BO-30 when applying the remetalizer "Rimet" is increased compared to those based on AO-20.

The remitalizer "Rimet" is practical to apply to friction couples with antifriction material base on AO-20 drather than matrials based on BO-30, because of the inability of nanoparticles to to get in the alloy.

\section{References}

1. L. Stanev, G. Komitov, Proceeding of ICMEN, 1, Tri06, 538 (2002).

2. L. Stanev, G. Komitov, Proceeding of University of Ruse „Angel Kanchev“, book 4.1 - Agricultural machinery and technologies. Agricultural science and 
veterinary medicine. Repair and reliability, 40, 183 (2003).

3. P. Kangalov, D. Beleva, K. Dyakova, Proceeding of University of Ruse „Angel Kanchev“, book 1.1 Agricultural engineering. Agricultural science and veterinary medicine. Repair and reliability. Ergonomic and design, 54, 218 (2015).

4. P. Kangalov, M. Nikolov, T. Delikostov, M.Stoyanov, Proceeding of University of Ruse „Angel Kanchev“, book 1.1 - Agricultural engineering. Agricultural science and veterinary medicine. Repair and reliability. Ergonomic and design, 54, 164 (2015).

5. http://rimetbg.com/product/rimet-nano-unificiran-50-ml/

6. L. Stanev, G. Komitov, Proceeding of XIII International Scientific Meeting Motor Vehicles \& Engines MVM 04, MVM04-A43, 317 (2004). 